ISSN: $2594-4827$

\title{
ESTÁGIOS CURRICULARES NO ENSINO DA ENFERMAGEM: ESPAÇO PRIVILEGIADO DE CONHECIMENTO
}

\section{Luis Fernando Rampellotti ${ }^{1}$}

Roberta Pasqualli ${ }^{2}$

RESUMO: A enfermagem atua no cuidado a vida humana, cujo contingente profissional é o maior da área da saúde. Este estudo objetiva discutir os estágios supervisionados na formação em enfermagem como o campo da prática e do trabalho e seu imprescindível caráter formativo. Trata-se de uma pesquisa bibliográfica, de caráter exploratório, como parte da revisão bibliográfica da pesquisa de mestrado "O bom docente enfermeiro: o olhar dos estudantes de cursos técnicos acerca dos saberes docentes", para a qual foram selecionados 26 artigos do Scientific Electronic Library Online - SCIELO, os quais continham as palavras "estágio" e "enfermagem". Deste foram selecionados 07 , em língua portuguesa e relacionados ao ensino em enfermagem. No ensino clínico de enfermagem o discente pode desenvolver diversas habilidades para a sua atuação profissional, sendo que, mesmo as dificuldades foram apontadas como momentos de adquirir características que fundamentam a atuação e as respostas a demandas do quotidiano e da práxis. O campo da prática figura como condição oportuna a aquisição de conhecimentos e sedimento do arcabouço teórico numa dinâmica de retroalimentação teoria-prática. A pesquisa sugere o aprofundamento do tema a partir de pesquisas exploratórias qualitativas, ouvindo os atores do processo de ensinoaprendizagem em enfermagem.

PALAVRAS CHAVE: Estágio clínico. Educação em enfermagem. Ensino.

\section{CURRICULAR STAGES IN NURSING EDUCATION: PRIVILEGED SPACE OF KNOWLEDGE}

ABSTRACT: Nursing acts in the care of human life, whose professional contingent is the largest in the health area. This study aims to discuss supervised internships in nursing training as the field of practice and work and its essential formative character. This is an exploratory bibliographical research, as part of the bibliographic review of the master's research "The good nurse teacher: the students' view of technical courses about the teaching knowledge", for which 26 articles were selected from Scientific Electronic Library Online - SCIELO, which contained the words "internship" and "nursing". Of these, 07 were selected in Portuguese and related to nursing teaching. In the clinical teaching of nursing students can develop several skills for their professional performance, and even the difficulties were pointed as moments of acquiring characteristics that support the performance and the responses to the demands of daily life and praxis. The field of practice includes the timely acquisition of knowledge and sediment from the theoretical framework in a theory-practice feedback dynamic. The

\footnotetext{
${ }^{1}$ Instituto Federal de Educação Ciência e Tecnologia de Santa Catarina - IFSC/Cerfead. E-mail: luis.rampellotti@gmail.com

${ }^{2}$ Instituto Federal de Educação Ciência e Tecnologia de Santa Catarina - IFSC/Cerfead. E-mail: roberta.pasqualli@ifsc.edu.br
} 
research suggests the deepening of the theme from qualitative exploratory research, listening to the actors of the teaching-learning process in nursing.

KEYWORDS: Clinical stage. Nursing education. Teaching.

\section{INTRODUÇÃO}

A profissão da enfermagem tem como atividade o cuidado a vida humana. $\mathrm{O}$ ofício desse profissional está fundamentado na relação entre aquele que cuida e aquele que necessita de cuidado a saúde ou de promoção desta. O fazer dessa classe é sempre uma interação entre vidas humanas e objetiva o atendimento a necessidades básicas do indivíduo das quais este está privado e as quais não pode corresponder sem auxílio de outro ser humano (HUF, 2002).

A referida classe profissional está dividida em enfermeiros, técnicos e auxiliares de enfermagem. Aos enfermeiros incumbe a coordenação e supervisão dos serviços de enfermagem, diagnóstico e prescrição de enfermagem, atividades de ensino e pesquisa, além da assistência direta a pacientes graves e em risco iminente de mote, entre outras atividades, por sua vez, os técnicos em enfermagem tem como principal atribuição a assistência direta aos pacientes, na execução dos chamados cuidados de enfermagem, enquanto o auxiliar de enfermagem realiza atividades de auxílio e apoio a equipe técnica sem realização de procedimentos de assistência direta (COREN, 2013).

Atualmente essa classe de profissionais da saúde figura como o maior contingente da área, totalizando no Brasil 2.140.550 profissionais, entre as três classes. Os técnicos em enfermagem são os mais numerosos, representando mais de $50 \%$ desse grupo, o que corresponde a 1.201.474 inscritos nos Conselhos Regionais de Enfermagem (COFEN, 2019).

A relevância do profissional de enfermagem está para além do contingente referido, sua atuação nos mais diversos serviços de saúde, garante qualidade de atendimento à população e melhoria da qualidade de vida. Sobretudo na atenção básica, do Sistema Único de Saúde - SUS, estes profissionais realizam um trabalho vital para a melhoria de vida da população brasileira. Do mesmo modo, em outros níveis de assistência em saúde - atenção secundária e terciária - estão presentes diuturnamente, garantindo a continuidade do cuidado (MORAES; CARDOSO, 2015).

Tais aspectos implicam diretamente a demanda pela qualidade na formação de novos contingentes profissionais de enfermagem. Sobre a formação destacamos que o 
profissional enfermeiro tem formação de nível superior, as outras duas classes são de nível médio, sendo a formação realizada por meio de cursos técnicos profissionalizantes. Durante a formação do profissional de enfermagem - de todos os níveis - está prevista como obrigatória a realização de estágios curriculares supervisionados em instituições de saúde (COREN, 2013).

A realização de estágios é apontada como importante ferramenta de ensino/aprendizado uma vez que permite romper a dicotomia teoria e prática, relacionando conteúdos teóricos à situações e problemas reais, bem como, realizar procedimentos em pacientes que demandam cuidados de enfermagem. Assim, a atividade de estágio supervisionado leva ao desenvolvimento de habilidades e o convívio com os profissionais em campo de trabalho, fomenta a observação crítica e ao contraponto entre academia e trabalho (EVANGELISTA; IVO, 2014).

Nesse sentido a aproximação discente com o mundo do trabalho, especificamente realizada por meio dos estágios e facilitados pelo professor supervisor, é de fato, uma forma de vencer o distanciamento e a estranheza entre os conteúdos teóricos e a práxis. Emana dos estudantes a queixa de muito conteúdo e pouca aplicação, os estágios constituem, portanto, o momento da aplicação, da transposição dos fundamentos da prática de enfermagem em execução do cuidado. Logo, os estágios constituem importante modalidade de ensino que visa a otimização do aprendizado da profissão (TIMOTEO; LIBERALINO, 2003).

Sendo assim, essa revisão bibliográfica tem por objetivo discutir os estágios supervisionados na formação em enfermagem, a partir da produção científica sobre o tema e discuti-lo a partir do diálogo com outros autores da educação profissional e tecnológica.

\section{PERCURSO METODOLÓGICO}

Trata-se de uma pesquisa de revisão crítica, uma vez que, analisa os achados de outros autores acerca da temática publicados em artigos científicos. Consiste em um estudo de caráter exploratório, analisando o tema, levantando informações e dialogando com outros autores (SEVERINO, 2016).

A revisão constituiu parte integrante da revisão bibliográfica da dissertação de mestrado intitulada "O bom docente enfermeiro: o olhar dos estudantes dos cursos 
técnicos acerca dos saberes docentes", do programa de mestrado em educação profissional e tecnológica - PROFEPT/IFSC.

Foram realizadas buscas no site de bancos de dados de trabalhos científicos SCIELO - Scientific Electronic Library Online, com os descritores "estágio" e “enfermagem", publicados nos anos de 2016 e 2017. Foram obtidos 26 resultados e, destes foram selecionados os artigos em língua portuguesa, cujos resumos permitiam relacionar seu conteúdo a atividades de ensino em enfermagem. Desse modo, a amostra emergiu da seleção de 07 artigos, os quais preenchiam esses critérios.

Os autores referidos foram os seguintes: Cunha (2017), Dall'Agnol, Oliveira e Cardoso (2017), Cunha, Macedo e Vieira (2017), Peixoto e Peixoto (2017), Silva et al (2017), Ribeiro, Pires e Scherer (2016), Damiance (2016).

A análise do material foi realizada com base na leitura crítica ou reflexiva do conteúdo dos artigos, a qual objetivou identificar as ideias dos autores acerca da temática explorada e a composição de fichamentos. Na sequência a leitura interpretativa buscou relacionar os pensamentos defendidos pelos autores com a questão em estudo. Por fim, a redação da discussão permite "pinçar das obras escolhidas os temas, os conceitos, as considerações relevantes para a compreensão do objeto de estudo" (LIMA; MIOTO, 2007).

$\mathrm{Na}$ sequência a discussão privilegiou as considerações dos autores consultados sobre o tema e dialogou com Vázquez (2011) e Barato (2015) por tratarem-se de autores da educação profissional que corroboram a dimensão formativa da prática, enriquecendo portanto, as considerações tecidas sobre este tema e fomentando a reflexão crítica acerca da temática.

\section{RESULTADOS E DISCUSSÃO}

O ensino clínico em enfermagem também chamado de estágios curriculares, constitui uma realidade oportuna nos cursos de formação profissional, uma vez que, as situações neles vivenciadas determinam a socialização com a profissão. Além de constituir o primeiro contato com a realidade do ofício a exercer, permite o desenvolvimento de habilidades a partir do desafio da aplicação do arcabouço teórico às situações reais de demanda profissional (PEIXOTO; PEIXOTO, 2017). 
A aplicação prática de conceitos abstratos e apenas ensinados a partir da verbalização apresenta-se como demanda imperativa no ensino das profissões. O contato com o mundo do trabalho, a oportunidade de vivência de situações reais, a execução da técnica, são fundamentais para que "certos valores aflorem", ou seja, para que características próprias ao profissional se desenvolvam no discente. Desenvolvimento que poderia ser chamado de construção da identidade profissional, a qual está vinculada ao seu fazer (BARATO, 2015).

Tais características podem também ser denominadas habilidades e, concernem as respostas que docentes e discentes fornecem às situações de desafios no curso do ensino em unidades de assistência à saúde. Portanto, o aluno é forjado profissional a partir da ponte entre sala de aula e os ambientes e situações nas quais é estimulado a aplicar seus conhecimentos na resolução de situações complexas que permeiam a assistência em saúde (PEIXOTO; PEIXOTO, 2017).

Cunha, Macedo e Vieira (2017) citam como aprendizados dos estágios para os discentes em enfermagem: o controle do nervosismo e ansiedade, aquisição de experiência, competência, novos conhecimentos, desenvolvimento da capacidade de improviso, tomada de decisão, resolução de problemas, aumento do sentido de responsabilidade, paciência e tolerância, flexibilidade, espírito de equipe e autonomia, preparação para o futuro, professores com experiência profissional, conhecimento extenso e atualizado, contato com a realidade hospitalar, alternância entre serviços, adaptação ao serviços, trabalhos com enfermeiros e equipes de enfermagem, prática em situações reais, aquisição de experiência e preparação para atuar, saber estar em contexto hospitalar, desenvolvimento da prática profissional, enfermeiros sensíveis às questões de como orientar ensino clínico.

Destacar tais contributos do ensino em situações práticas, reitera e corrobora o caráter de contribuição social dos conhecimentos para o fazer profissional, para o potencial transformador da prática e gerador de demandas teóricas. Em outras palavras a prática é caracterizada como “[...] ação material, objetiva, transformadora, que corresponde a interesses sociais e que, considerada do ponto de vista histórico-social, não é só produção de uma realidade material, mas, sim, criação e desenvolvimento incessantes da realidade humana" (VÁZQUEZ, 2011). 
Nesta perspectiva, Vázquez (2011) sinaliza que o ensino da prática se torna imprescindível à formação profissional. Embora as teorias sejam o fundamento da execução do ofício, o saber fazer somente vai sendo construído paulatinamente às demandas do ambiente de atuação profissional, o qual é dinâmico e altamente mutável a determinações e períodos históricos e sociais.

Assim, as experiências em campo de estágio vão constituindo situações reais de aprendizado, como apontam Cunha, Macedo e Vieira (2017). Os autores afirmam que nos estágios em enfermagem as fragilidades e problemas surgidos nos ambientes de ensino clínico, sinalizam a supervisão de enfermagem como importante mediador de resoluções e de transformação dessas realidades em aprendizado. Corroboram essa afirmação Ribeiro, Pires e Scherer (2016), os quais interpretam as adversidades encontradas em campo de estágio como fomento à criatividade e tomada de decisão.

Esse estímulo ao desenvolvimento de habilidades pessoais e conhecimento profissional, pode ser mediado também por situações nas quais o docente propõe resolução de problemas, elaboração de plano de cuidados, estudos de casos e às próprias situações clínicas que surgem no campo. Surgem, portanto, situações reais de aprendizado, nas quais docente e discente trabalham para a apropriação e domínio do campo de trabalho dessa classe profissional, através de aproximação e dissolução de estranhamentos e dúvidas (PEIXOTO; PEIXOTO, 2017; DALL'AGNOL; OLIVEIRA; CARDOSO, 2017).

O campo da prática é, portanto, o território da tensão, uma vez que desafia à superação da cisão teoria e prática. Esse desconforto tem origem na saída do ambiente escolar ou acadêmico para o mundo do trabalho, cuja complexidade e dinâmica imperam a ressignificação do aprendizado. Desse modo, esses processos formativos constituem a 'socialização' profissional, no encontro com o fazer em si, com a aplicação, e evidentemente, com os outros seres envolvidos no processo, quer de estudo, quer de atuação e trabalho (CUNHA; MACEDO; VIEIRA, 2017).

Ribeiro, Pires e Scherer (2016) atribuem ao trabalho e, portanto, a aproximação do estudante ao mundo da prática de seu ofício, a "renormalização" dos enunciados teóricos. Em outras palavras, as demandas experimentadas na atuação prática levam a tomada de decisão aliada aos conhecimentos teóricos e experienciais. 
Em outras palavras, as necessidades do trabalho motivam a busca pelo conhecimento. A prática enriquece a teoria e é capaz de fundamentá-la, uma vez que, o conhecimento progride a medida em que os homens dominam e se apropriam de suas intervenções na realidade. As demandas geradas na e pela execução das atividades humanas, influenciam o desenvolvimento das teorias que a subsidiam, explicam e criam idealmente. O profissional em formação tem na teoria a composição ideal do ser profissional e de seu fazer, ao passo em que a aplicação dá sentido ao conhecimento,

Do papel determinante da prática - como fundamento, fim e critério do conhecimento verdadeiro - não se pode extrair a conclusão de que a teoria e a prática se identifiquem, ou de que a atividade teórica se transforme automaticamente em prática. Impede chegar a essa conclusão o fato de que a prática não fala por si mesma e exige, por sua vez, uma relação teórica com ela: a compreensão da práxis. (VÁZQUEZ, 2011)

Para Vázquez (2011) portanto, não há uma relação de hierarquização entre teoria e prática. $\mathrm{O}$ autor esclarece que há uma relação de interdependência e complementariedade. Nesse sentido, defende que a prática clarifica e enriquece a teoria, ao mesmo tempo em que está ancorada nos princípios teóricos.

O estágio, portanto, insere-se nessa ponte entre conhecimento teórico e prático, para o qual contribui a interação com as equipes dos locais onde os estágios são desenvolvidos, sendo determinantes para o bom êxito das atividades estudantis. A postura dos profissionais que recebem equipes de estágio também reflete nas atividades de ensino e aprendizagem. Desse modo, as dificuldades de acesso aos profissionais do local, podem constituir em algumas situações, oportunidade de crescimento ao defrontar-se com a adversidade. Do mesmo modo, a acolhida e empatia das equipes que recebem estagiários de enfermagem, promove interação e partilha de conhecimentos e experiências, favorecendo também a atualização daqueles já atuantes (DALL'AGNOL; OLIVEIRA; CARDOSO, 2017).

As atividades de ensino clínico fomentam a geração e a apropriação de conhecimento quando há uma retroalimentação dinâmica entre os conteúdos explorados em sala de aula e as vivências da prática, as situações práticas de ensino estimulam os alunos a que "produzam conhecimento situado e aprendam a lidar com a natureza 
complexa, indeterminada e única da sua profissão”. Obviamente os conteúdos são importantes por embasarem a prática e instrumentalizarem a tomada de decisão, contudo, da prática emanam questões, necessidades e contributos a serem explorados pela academia, justificando a mútua alimentação para a construção do conhecimento profissional (CUNHA; MACEDO; VIEIRA, 2017).

Para Vázquez (2011) a teoria consiste em "esclarecimento e guia de uma práxis que, por sua vez, a fundamenta e enriquece”, essa proposição reitera a retroalimentação entre teoria e prática e sua indissociabilidade para a construção do conhecimento.

Do mesmo modo, estudo de Silva et al (2017) corrobora a importância dos estágios, e portanto, do ensino prático, para sedimentar os conteúdos da profissão e das áreas de conhecimento específicas. Nesse sentido, o relato da mudança do perfil do cuidado e da qualidade impressa à disciplina de enfermagem psiquiátrica na Escola Anna Nery, a partir da obrigatoriedade de estágios em instituições de assistência psiquiátrica, corrobora a importância do ensino de enfermagem a partir do contato com situações de assistência reais.

Tais situações de ingresso em ambientes reais de trabalho, propiciam observação, integração, relação com os pares, inserção na realidade do ofício para o qual se prepara o discente, de modo que Barato (2015) os define como

Ambientes de trabalho/aprendizagem, além de oferecerem um cenário para aprendizagens significativas, são locais onde as demandas de produção geram interações entre os atores sociais. São justamente essas interações que concretizam a negociação de significados que se desdobram em gestos de apreciação da obra e cooperação (ou, eventualmente, conflito) entre os atores sociais. (BARATO, 2015)

Nesse sentido, o relacionamento e interação interpessoal corroboram a liderança e a autonomia, e a apropriação do papel a desempenhar na equipe. O desenvolvimento do estágio deve ser acompanhado de maior interação às equipes e a dinâmica e organização dos processos de trabalho da enfermagem (DALL'AGNOL; OLIVEIRA; CARDOSO, 2017; DAMIANCE, 2016).

Silva et al (2017) sinaliza a presença do docente em enfermagem e sua contribuição para a experiência discente e para fomentar reordenamentos na assistência prestada, a partir do reconhecimento que obtém da equipe, do mesmo modo, Cunha, 
Macedo e Vieira (2017), ratificam a atuação do docente supervisor como determinante para oportunizar experiências enriquecedoras em campos de estágio.

Os autores supracitados são unânimes ao apontarem o docente enfermeiro como mediador das situações que fomentam o aprendizado dos estagiários em enfermagem. A figura do professor torna-se referência, tanto a equipe da unidade onde as atividades de ensino aprendizagem práticas estão sendo realizadas, quanto para a comunidade discente. O juízo que o professor faz das situações vivenciadas em campo, as contribuições para a melhoria da assistência prestada e as observações tecidas aos alunos constituem fatores contribuintes da experiência deste à construção profissional dos alunos e a troca de saberes e vivências com a equipe que recebe os estagiários.

Ainda acerca das equipes que recebem as atividades de ensino clínico, possuem uma dimensão formadora, ainda que por vezes, involuntária. Os alunos veem neles - ou buscam ver - a materialização das características e prática do profissional e da profisssão. Em outras palavras, o estagiário observa e apreende a postura e prática profissionais, além de adquirir habilidades para o relacionamento, comunicação e trato interpessoal (DALL'AGNOL; OLIVEIRA; CARDOSO, 2017).

Os profissionais já iniciados no ofício representam para Barato (2015), a comunidade de prática dos formandos, os quais procuram se identificar com aqueles por meio da indumentária, por exemplo, na área da saúde o uso do branco. Aspecto que se insere na construção da identidade profissional e da imersão no mundo do trabalho como elementos formadores e de fomento ao desenvolvimento humano e profissional.

Para além de aspectos exteriores, como a indumentária e os instrumentos, a imersão e paulatinamente a inserção na comunidade de ofício, imputam aos formandos os valores da profissão, a postura e a consciência coletiva, aspectos que rementem às questões identitárias. A partir da inserção nos ambientes de prática - a oficina, para a enfermagem os laboratórios, os hospitais, as clínicas, enfim, os locais onde se executa o cuidado profissional - o educando vai se tornando profissional, adquirindo habilidades, posturas, aprendendo a ser como aqueles com os quais convive e passa a se identificar (BARATO, 2015).

Especificamente a formação de enfermagem em nível superior requer preparação para a liderança, a tomada de decisão, julgamento clínico e resolução de problemas, para as quais são imprescindíveis as situações que desafiam a construção do pensamento 
crítico nos ambientes reais de atuação, situações oportunizadas pelos estágios. Do mesmo modo, a formação técnica, a partir dessa experiência, também adquire "responsabilidade e qualidade profissional" (PEIXOTO; PEIXOTO, 2017).

Esses aspectos apontam para a aquisição de domínios e aprendizados por parte dos discentes, que não ocorrem apenas pela abstração e fundamentação teórica, porém, dependem de situações reais de aplicação e julgamento que oportunizem a tomada de decisão fundamentada por sua vez nas teorias. Tais situações são nomeadamente os problemas da assistência, as demandas dos pacientes e das equipes de enfermagem e os desafios do planejamento e execução do planejamento de cuidados de enfermagem.

As vivências em campo de estágio oportunizam e contribuem para o desenvolvimento de habilidades como a liderança, comunicação, flexibilidade entre enunciados teóricos e realidade assistencial, enfim, recursos que empoderam o futuro profissional a resolver problemas inerentes a sua prática profissional cotidiana. Os estágios constituem, portanto, instrumentos de ensino à "construção de soluções criativas e ajustadas" as mais diversas situações profissionais (CUNHA; MACEDO; VIEIRA, 2017).

Sob o aspecto da qualidade, Dall'Agnol, Oliviera e Cardoso (2017), destacam que alunos empenhados no campo contribuem para a dinâmica do trabalho, das equipes e determinam melhora da qualidade do serviço e assistência de enfermagem, o mesmo referido por Silva et al (2017). Tais aspectos corroboram a dimensão da troca entre equipe residente e equipe de estágio. De modo que, entre os sujeitos envolvidos nos processos de ensino da enfermagem se estabelece uma relação de mútua contribuição, tanto os profissionais aprendem e ensinam quanto os discentes, e assim, os estágios oportunizam um diálogo entre a academia, as universidades e as escolas técnicas e os locais de trabalho onde se dá a assistência de enfermagem.

No âmbito do Sistema Único de Sáude - SUS - essa mútua cooperação se exemplifica a partir das atividades de ensino clínico, as quais são realizadas em parceria com as instituições de serviço visando a colaboração entre docentes, discentes e as atividades do SUS, propiciando aos alunos uma formação com uma visão e abordagem integrais do processo saúde-doença. Assim, ao mesmo tempo em que contribui para a formação em saúde, propicia estágios com níveis de complexidade desafiadores e altamente enriquecedores para atividades de ensino aprendizado. Havendo, portanto, 
contribuição mútua, quer das atividades de estágio para as instituições, quer das instituições para oportunizar aprendizado aos estagiários (DAMIANCE et al, 2016).

As atividades de contatos iniciais com a profissão contribuem também ao desenvolvimento de hábitos e práticas seguras, como por exemplo, a adesão as medidas de biossegurança. $\mathrm{O}$ ensino clínico visa ainda a sensibilização discente a adesão a uma cultura de assistência segura (RIBEIRO; PIRES; SCHERER, 2016). Aspectos que dialogam com Barato (2015) para quem a oficina, e portanto, o ensino mediado pelo trabalho, corroboram a incorporação da postura e dos hábitos da profissão. Portanto, a sensibilização para o uso de dispositivos de segurança no trabalho, a adoção e a adesão a protocolos de segurança da assistência, são iniciados na e pela formação profissional, sobretudo, no contato com o mundo do trabalho.

A adesão a princípios e valores profissionais, bem como, a práticas orientadoras para a vida, constituem, portanto, outro benefício da imersão em ambientes de prática e trabalho, ratificando uma vez mais, a contribuição decisiva do ensino da práxis para a formação dos profissionais (BARATO, 2015).

\section{CONSIDERAÇÕES FINAIS}

O estudo permitiu reconhecer o campo da prática como fonte de conhecimento e sedimentação do arcabouço teórico recebido na formação em sala de aula. As vivências que os alunos experimentam na realidade de ensino clínico fundamentam sua postura atitudinal na vida profissional.

O ambiente de trabalho em enfermagem é desvelado pela proposição de atividades práticas e desafios por parte dos docentes e do próprio campo. O convívio com os preceptores e com os profissionais de enfermagem do setor onde se desenvolve o estágio, estimulam o desenvolvimento de hábitos e da identidade profissional, os quais estão diretamente relacionados ao saber fazer profissional.

O ensino clínico é responsável por fomentar o desenvolvimento de diversas habilidades, havendo destaque na formação para a liderança, o relacionamento e a comunicação interpessoal a tomada de decisão e o raciocínio clínico. Também as dificuldades em campo de estágio, despontam como oportunidades de desenvolver características pessoais importantes para a superação das demandas próprias ao quotidiano profissional. 
A prática e o trabalho surgem como oportunidades formativas, nas quais a teoria fundamenta e idealiza a práxis, enquanto essa, estimula e demanda a busca pelo conhecimento e suas invocações, havendo uma retroalimentação teoria-prática. Desse modo, o campo de estágio se configura o local e a situação privilegiada para discentes e discentes realizarem esse diálogo entre academia, universidade, escola técnica e o mundo do trabalho.

O estudo levantou discussões oportunas para o ensino em enfermagem que podem fomentar o aprofundamento da temática posteriormente por meio de trabalhos qualitativos, exploratórios, descritivos, realizados nos locais de ensino clínico, envolvendo e ouvindo os atores do processo, por exemplo, e não apenas limitados a revisão teórica. Assim, ter-se-ia um panorama mais ampliado sobre o tema.

\section{REFERÊNCIAS}

BARATO, Jarbas Novelino. Fazer bem feito. Valores em educação profissional e tecnológica. Brasília: UNESCO, 2015. 219 p. Disponível em:

〈http://unesdoc.unesco.org/images/0023/002336/233600POR.pdf> Acesso em: março 2018

CONSELHO FEDERAL DE ENFERMAGEM - COFEN (WEB). Pesquisa inédita traça perfil da enfermagem. 2019 Disponível em: <http://www.cofen.gov.br/pesquisainedita-traca-perfil-da-enfermagem 31258.html $>$ Acesso em março 2019

CONSELHO REGIONAL DE ENFERMAGEM DE SANTA CATARINA (CORENSC). Consolidação da Legislação e Ética Profissional / organizadoras Denise Elvira Pires de Pires et al. 2.ed. Florianópolis: Conselho Regional de Enfermagem - SC: Quorum Comunicação, 2013. 132 p.: il. - (Cadernos de Enfermagem; v. 1)

CUNHA, Carmem Maria dos Santos Lopes Monteiro da; MACEDO, Ana Paula Moraes de Carvalho; VIEIRA, Isabel Flavia Gonçalves Fernanda Ferreira. Percepções dos estudantes de enfermagem sobre os processos formativos em contexto de ensino clínico. Revista de Enfermagem Referência. Série IV n.12 Jan-Fev-Mar 2017. Disponível em: $<$ http://www.scielo.mec.pt/scielo.php?script=sci abstract\&pid=S087402832017000100 0 08\&lng=pt\&nrm=i so\&tlng=en>. Acesso em: junho de 2018.

DALl'AGNOL, C. M.; OLIVEIRA, A. P.; CARDOSO, A. S. F. Estágio de administração em enfermagem: repercussões para a equipe em unidades clínico cirúrgicas. Revista Gaúcha de Enfermagem. v. 38. n.02. 2017. versão online. Disponível em:

$<$ http://www.scielo.br/scielo.php?script=sci_arttext\&pid=S198314472017000200406\& lang=pt $>$ Acesso em junho de 2018 
ISSN: $2594-4827$

DAMIANCE, Patricia Ribeiro Mattar; et al. Formação para o SUS: uma análise sobre as concepções e práticas pedagógicas em saúde coletiva. Trabalho educação e saúde. Rio de Janeiro. V. 14 n. 3 p. 699-721. Set/Dez 2016. Disponível em: < http://www.scielo.br/scielo.php?pid=S1981- 77462016000300699\&script=sci abstra ct\&tlng=pt >. Acesso em: junho de 2018.

EVANGELISTA, D. L.; IVO, O. P. Contribuições do estágio supervisionado para a formação do profissional de enfermagem. Revista Enfermagem Contemporânea. Dez 2014. v.3 n.2 p. 123-130. disponível em:

<https://www5.bahiana.edu.br/index.php/enfermagem/article/view/391/340> Acesso em junho 2018.

HUF, D. D. A face oculta do cuidar: reflexões sobre a assistência espiritual em enfermagem. Rio de Janeiro: Mondrian. 2002. 208.

LIMA, T. C. S.; MIOTO, R. C. T. Procedimentos metodológicos na construção do conhecimento científico: a pesquisa bibliográfica. Revista Katálysis. Florianópolis v. 10 n. esp. p. 37-45. 2007. Disponível em:

< http://www.scielo.br/pdf/rk/v10nspe/a0410spe > Acesso em: junho de 2018

MORAES, Roseli Gabriel Amâncio; CARDOSO, Adilson Lopes. A necessidade de preparo pedagógico do enfermeiro para atuar na formação de profissionais da área da saúde com ênfase na enfermagem. Revista de teorias e práticas educacionais. v. 7, n. 1, p. 14-20. 2015. Disponível em:

<https://www.mastereditora.com.br/periodico/20150821 153134.pdf> Acesso em: 16 nov. 2017.

PEIXOTO, Tiago Andre dos Santos Martins; PEIXOTO, Nuno Miguel dos Santos Martins. Pensamento Crítico dos Estudantes de Enfermagem em Ensino Clínico: uma revisão integrativa. Revista de Enfermagem Referencia. Série IV. n.13 p. 125-138. Abril Maio Junho 2017. Disponível em: < http://www.scielo.mec.pt/pdf/ref/vse rIVn13/serIVn13a13.pdf>. Acesso em: junho de 2018.

RIBEIRO, Gerusa; PIRES, Denise Elvira Pires de; SCHERER, Magda Duarte dos Anjos. Práticas de Biossegurança no Ensino Técnico de Enfermagem. Trabalho Educação e Saúde. Rio de Janeiro. v.14. n.3. p.871-888. Set/Dez 2016. Disponível em: $<$ http://www.scielo.br/scielo.php?pid=S1981-

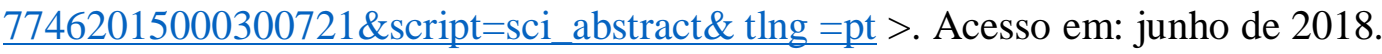

SEVERINO, Antônio Joaquim. Metodologia do Trabalho Científico. 24. ed. São Paulo: Editora Cortez, 2016.

SILVA, Barbara Tavares; et al. Instituto de psiquiatria da Universidade do Brasil como campo de estágio da Escola Ana Nery (1954 - 1962). Escola Ana Nery. Rio de Janeiro v.21. n.3. 2017. Disponível em: < http://www.scielo.br/scielo.php?pid=S1414-

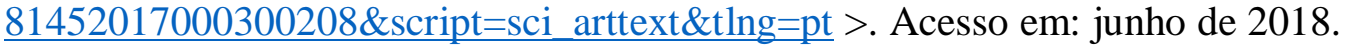

TIMOTEO, R. P. S.; LIBERALINO, F. N. Reflexões acerca do fazer pedagógico a partir de referências e diretrizes educacionais para a formação em enfermagem. Revista 
Brasileira de Enfermagem. jul-ago 2003. v.56 n. 4 p. 358-360. Disponível em: <http://www.redalyc.org/pdf/2670/267019641008.pdf> Acesso em junho de 2018.

VÁZQUEZ, A. S. Filosofia da práxis. 2 ed. Buenos Aires: Consejo Latinoamericano de Ciencias Sociales - Coleção pensamento social Latino-Americano: São Paulo: Expressão Popular, Brasil, 2011. 448 p. 